\title{
Microemulsion Oil Displacement Effect of Fracture Reservoirs
}

\author{
Jiangfen Jia*, Zhengdong Xu, Bin Zhang, Peng Wang, Weizhong Kong, Zhiyuan Xu, Wei Xiong, Yuanzhao Jia, Jiefeng \\ Cao \\ Engineering Technology Research Institute of Huabei Oil Company, Renqiu city, Hebei province, 062550, China
}

\begin{abstract}
In order to compare the oil repellent effect of microemulsion drive and water drive, the remarkable effect of improving recovery rate of microemulsion drive is proved from the microemulsion aspect by analyzing the crack core oil drive experiment and the distribution law of the residual oil in the pore. The experimental results show that the yield rate of microemulsion drive can increase by $10.8 \%$ compared with the water drive, and the final recovery rate is as high as $49.7 \%$, which shows that the recovery rate of microemulsion drive system has a significant effect. The proportion of residual oil with pore decreased with the decrease of pore radius, which shows that the pore radius has a significant effect on the distribution of residual oil. And compared with the matrix core, the proportion of residual oil pore in the fissure core is larger and the oil removal efficiency is relatively low.
\end{abstract}

\section{Introduction}

China's medium and low-permeable reservoir reserves are huge, and with high development difficulty. From a technical point of view, microemulsion drive is most suitable for three oil recovery, and is an effective technology for water injection development[1-2]. Microemulsion drive is not limited by water content, which can obtain a high water drive residual oil recovery rate[3]. Microemulsion drive mainly improves recovery rate through six aspects, namely, reducing oil-water interface tension, emulsified mixed phase, gathering and forming oil belt, changing wetting of rock surface, increasing surface charge density, and changing the flow variability of crude oil[4-5]. The effect of microemulsion system on improving recovery rate of crude oil is verified by using oil drive experiment and analysis of pore residual oil, and the foundation is laid for the low permeable reservoir to improve recovery rate.

\section{Experimental design}

\subsection{Experimental instruments and drugs}

Experimental materials: crack core of the First oil proudution plant in Huabei oilfield, First oil proudution plant in Huabei oilfield crude oil and kerosene according to a certain proportion of preparation, mineralization of $6778 \mathrm{mg} / \mathrm{L}$ of simulated salt water.

Experimental drugs: positive octane, pyridine beetroot, positive butanol, $\mathrm{NaCl}$.

Experimental instruments: MS3000 laser granularizer, TX500C screw-drop interface tension meter, vacuum pump, insulation box, core gripper, piston container, ring pressure pump.

\subsection{Experimental procedure}

The oil repellent experiment is shown as follows. Select out the optimal microemulsion system as the repellent, Huabei oilfield low-permeable reservoir crack core for the drive-up core according to the following steps to carry out the oil drive experiment. (1) To pump the core of the core and saturate the simulated formation water under vacuum conditions to determine its permeability and pore volume. (2) To use simulated oil for reusiving until the end of the core is no longer watery, and to determine its oil saturation. (3) To use simulated brine to repel until the water content in the extracted liquid reaches $98 \%$, then the section plug of $0.3 \mathrm{PV}$ is transferred, and then the subsequent water drive is carried out until the water content in the extracted liquid reaches $98 \%$ again.

The core anatomy experiment is shown as follows. (1) The crackcore heart of the exorcism experiment will be broken to obtain the natural section of the core. (2) The microscopic natural section of the core was taken using a microscopic microscope to calculate the size of the core pore radius. And studying the relationship between the pore radius and the oil drive efficiency to analyze the distribution of residual oil in the pore.

\section{Experimental Results and Analysis}

\subsection{Injecting pressure}

The graph ingested volume multiple and injection pressure are plotted as shown in Figure 1. 


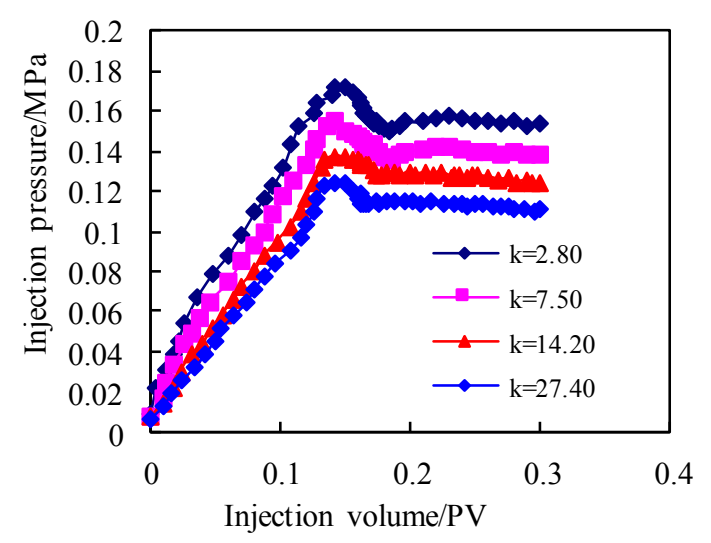

Figure1.Injection pressure of cores with different permeability

According to the above experimental results, the injection pressure begins to rise rapidly during a water drive, because the fluid in the low-permeable reservoir needs to overcome the starting pressure to flow. After injecting the microemulsion, the injection pressure begins to decrease, mainly because the ultra-low interface tension of the microemulsion can reduce the starting pressure gradient and reduce the resistance of the drive to drive. Make the oil droplets easier to enter the small throat, thereby increasing the recovery rate. The subsequent water drive, the injection pressure gradually leveled off, because the microemulsion drive stage, reducing the adhesion of crude oil on the rock surface so that the oil film on the rock surface peeled off with the oil droplets to be removed. And in the subsequent water drive, some of the oil droplets and formed oil belt and was driven out. The greater the penetration, the smaller the injection pressure.

\subsection{Oil repellent effect}

The relationship between water cut and degree of extraction and experimental results are shown in Figure 2.

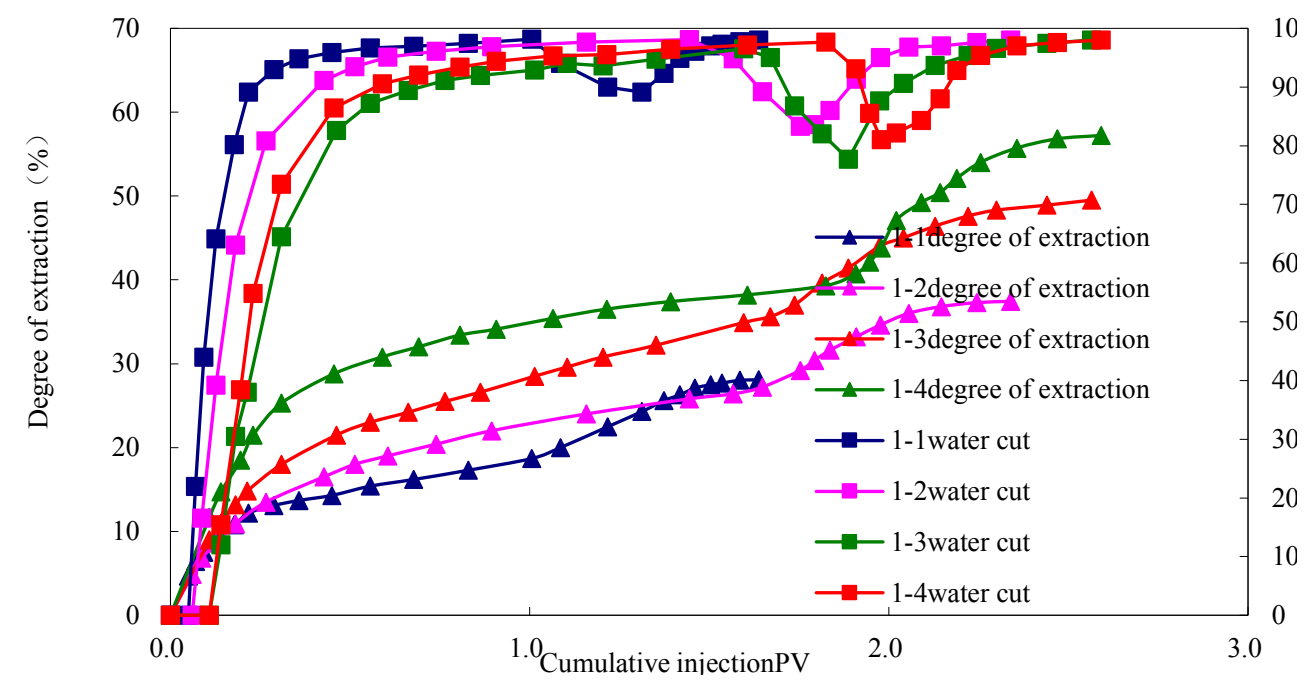

Figure2.Core flooding effect diagram

As can be seen from Figure 2, the water content is 0 when the early water injection, and at this time the output liquid contains only oil. With the accumulation of the cumulative injection PV, the moisture content gradually increased. When the water content increase to $98 \%$ to injected microemulsion system, then the water content began to decrease, and reached the lowest point gradually increased until the level. In the early stage of water injection, the degree of extraction increased rapidly with the increase of the cumulative injection multiple, and the increase of the degree of extraction during the high water content period was relatively slow. When the microemulsion system was injected, the degree of extraction rose sharply with the decrease of water content The recovery speed and the recovery rate increased significantly.

Table1. Experimental settlement of fractured core oil displacement experiment

\begin{tabular}{cccccccc}
\hline $\begin{array}{c}\text { Core } \\
\text { No }\end{array}$ & $\begin{array}{c}\text { Matrix } \\
\text { Permeability } \\
/ 10^{-3} \mu \mathrm{m}^{2}\end{array}$ & $\begin{array}{c}\text { Crack } \\
\text { Permeability } \\
/ 10^{-3} \mu \mathrm{m}^{2}\end{array}$ & $\begin{array}{c}\text { Porosity } \\
/ \%\end{array}$ & $\begin{array}{c}\text { Water drive } \\
\text { recovery rate/\% }\end{array}$ & $\begin{array}{c}\text { Minimum water } \\
\text { content } / \%\end{array}$ & $\begin{array}{c}\text { Increase in } \\
\text { recovery rate/\% }\end{array}$ & $\begin{array}{c}\text { Final recovery } \\
\text { rate/\% }\end{array}$ \\
\hline $1-1$ & 2.8 & 27.6 & 15.3 & 18.5 & 89.3 & 6.2 & 24.1 \\
\hline $1-3$ & 7.5 & 67.5 & 17.4 & 26.1 & 86.5 & 8.5 & 34.6 \\
\hline $1-4$ & 14.2 & 127.8 & 18.1 & 35.2 & 81.1 & 9.4 & 45.3 \\
\hline $1-5$ & 27.4 & 246.6 & 20.6 & 38.9 & 78.6 & 10.8 & 49.7 \\
\hline
\end{tabular}

From the microemulsion oil drive experiment can be concluded that the microemulsion drive relative to the water drive, the final recovery rate of microemulsion drive increased from $24.1 \%$ to $49.7 \%$.It can be seen that the recovery rate increased significantly, and with the 
increase of penetration, the increase of recovery rate gradually increased, which indicating that microemulsion drive significantly improved recovery rate.

Using the crack core of Huabei oilfield with different permeability to carry out microemulsion oil drive experiment, and then the average pore radius of each core

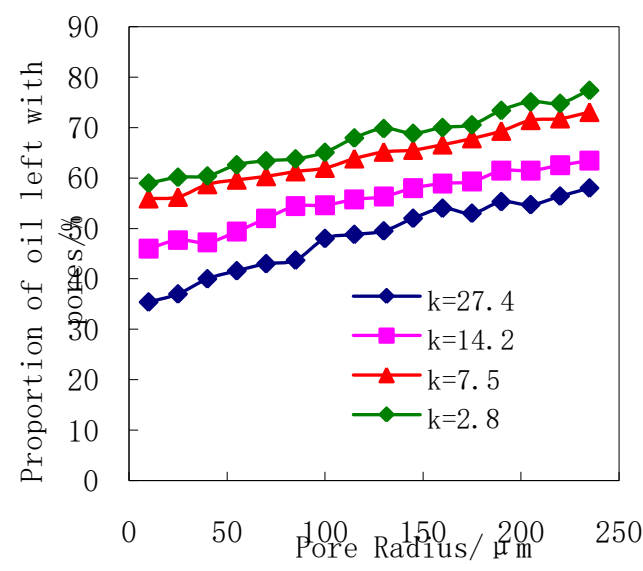

(a) was measured by the core of the core. The pore radius was divided into different levels, and the proportion of residual oil pore was defined as the residual oil of the pore. Plot the relationship curve between the average pore radius and the oil drive efficiency.

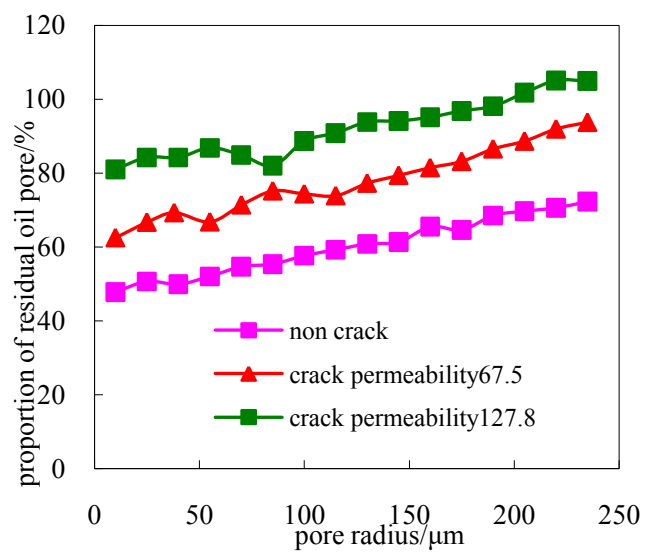

(b)

Figure3. The relation curve of pore radius and the proportion of residual oil pore

As can be seen from Figure 3(a), the proportion of cores with residual oil pores at different permeability levels decreases with the reduction of pore radius. Under the condition of the same pore radius, the proportion of pores with residual oil decreased with the increase of permeability. The permeability of the core matrix increased from $2.8 \times 10^{-3} \mu \mathrm{m}^{2}$ to $27.4 \times 10^{-3} \mu \mathrm{m}^{2}$, and the proportion of the volume of the residual oil pore decreased from $79.86 \%$ to $31.23 \%$, and the different pore radius had a significant effect on the distribution of the remaining oil. The hair pipe force for wet rocks in the oil drive process is the driving force, and the hair pipe force increases with the reduction of the pore radius, so the repellent first enters the pore with a smaller radius, then reducing the proportion of oil remaining in the pore. As can be seen from Figure 3(b), with the increase of the penetration of the cracks, the proportion of the remaining oil pores corresponding to the same pore radius is also increased. The small seepage resistance of the micro-cracks is the advantage channel of the two-phase flow of oil and water, which will lead to the injection of water along the cracks and accelerate the formation of invalid cycle channels, then making the crude oil in the pore more difficult to be replaced, so the remaining oil will increase accordingly.

Compared with the non-crackcore core, the crack has a very important influence on the oil removal efficiency of the core, and the oil removal efficiency is reduced. Due to advantage of the small seepage resistance of micro-cracks, especially when the matrix around the micro-crack is poor, then the seepage advantage is more obvious. Injection fluid along the crack flow which can accelerate the formation of invalid circulation channel, then a large number of residual oil will remain in the matrix pore to result low efficiency. It is characterized by an increase in oil removal efficiency with the increase of the penetration of the crack.

\section{Conclusions}

(1) It is learned from the oil drive experiment that the injection pressure of microemulsion is relatively small, and the increase of recovery rate increases with the increase of penetration rate. Compared with water drive, the permeability rate of core from $2.8 \times 10^{-3} \mu \mathrm{m}^{2}$ increased to $27.4 \times 10^{-3} \mu^{2}$, and the final recovery rate of microemulsion drive increased from $24.1 \%$ to $49.7 \%$, and the maximum recovery rate increased by $10.8 \%$, which indicates that the micro emulsion drive improved the recovery rate significantly.

(2) The proportion of pores containing the remaining oil decreased with the decrease of the average pore radius, which indicates that the pore radius has a significant effect on the distribution of the remaining oil. Compared with the matrix core, the proportion of residual oil pores in the crack core is relatively large, and the oil removal efficiency is relatively low.

\section{Acknowledgments}

The project is supported by Huabei oilfield scienticfic research project (No. 2019-HB-C10 and No. 2018-HB-C11). We would like to thank the staff of engineering technology research institute of Huabei oilfield.

\section{References}

1. Zhou, Y., Pan, Z.W., Chen, G. (2016) Synthesis and Properties of A Novel Amphoteric Betaine Surfactant. J. Chinese Journal of Synthetic Chemistry, 24: 5-62.

2. Qiao, M.Z., Zhao, N., Zhao, Y.J. (2017) Synthesis of 
dianionic surfactant and its flooding effect.J.Oilfield Chemistry, 34:113-118.

3. Wang, R.J.,Xue, B.Q.,Lu, X.G. (2015) Formulation optimization and oil displacement effect evaluation of poly/surfactant binary composite system. J. Oilfield Chemistry, 32:108-113.

4. Wang, Q.M., Sui, J., Ji, B.F. (2001) Practice and understanding of tertiary oil recovery technology in Daqing Oilfield. J. Petroleum Geology and Oilfield Development in Daqing, 20:1-8.

5. Wang, K.L., Shen, T., Liu, H.O. (2017) Displacement characteristics of different oil displacement systems in Bailey cores. J. Petroleum Geology and Oilfield Development in Daqing, 36:90-94. 